\title{
Curriculum Exchange: Engineering Speed Dating: An introduction to the disciplines of engineering
}

\section{Dr. Alandra Kahl, Pennsylvania State University, Greater Allegheny}

Dr. Alandra Kahl currently teaches engineering design and sustainable systems at The Pennsylvania State University, Greater Allegheny campus. She received her doctorate in environmental engineering from the University of Arizona in 2013, where her dissertation focused on the fate and transport of contaminants of emerging concern in an arid region. Dr. Kahl's research interests include engineering of sustainable systems, treatment of emerging contaminants via natural systems and engineering education. She is the author of several technical papers and conference proceedings centered on environmental engineering. Her professional affiliations include the American Society of Civil Engineers, the American Chemical Society, and the American Society for Engineering Education. 
Title: Engineering Speed Dating: An introduction to the disciplines of engineering (Curriculum Exchange)

Target grade level: $9-12$

Author's name and contact info: Dr. Alandra Kahl, Penn State Greater Allegheny; afk12@psu.edu

Curriculum summary:

High school students are often overwhelmed by the proliferation of specialties available to them in the realm of engineering. It is often the approach of the instructor to lecture to the students directly, rather than allowing them to explore the areas for themselves. To meet this need, an activity was developed to expose students to the various disciplines of engineering in an innovative and engaging way. Students in a high school level introduction to engineering class were given giant whiteboards headed with the various disciplines and allowed a short interval in which to write words or phrases with which they associated the discipline. Following the activity, the words were collected to form word clouds, which were then discussed with the students. Participants were given short pre- and post-surveys to assess the impact of the activity on student awareness of the different disciplines by collecting quantitative and qualitative data.

The speed dating approach grew out of the need for high school students to be introduced in the varying disciplines of engineering in an interactive way. It is based on the idea of speed dating- a concept that was first introduced in 1998 by Rabbi Yaacov Deyo of Aish HaTorah, originally as a way to help Jewish singles meet and marry. This activity was inspired by the outreach activity "Scientist Speed Dating" from the Nanoscale Informal Science Education Network (http://www.nisenet.org/catalog/programs/scientist_speed_dating) where scientists talk about their work to the public in a speed dating format.

Prior to the start of the activity, students are asked to fill out a survey that asks them to state their familiarity with engineering disciplines. For the activity, students are rotated to "meet" each discipline of engineering which is displayed as a heading on a giant white board. Students are given markers and instructed to write as many words or phrases associated with the discipline as they can during the time interval of two minutes, using a kitchen timer. Following the conclusion of the rotation period, the whiteboards were collected and the writings used to generate word clouds. The following class period, the word clouds were shown to the students and discussed by the instructor. Students benefited from having misconceptions (many associated chemical engineering with the TV show "Breaking Bad" for example) explained as well as learning indepth about unfamiliar disciplines such as industrial engineering. Following the lecture, students were again surveyed regarding their understanding and awareness of the different disciplines of engineering, with results showing overall improvement in content knowledge. The materials that 
will be demonstrated will consist of an example activity setup, prompts for which to help students brainstorm words, example student word clouds, and pre/post example surveys and data. If there is time, teachers will try out the activity and generate an example word cloud. 